\title{
COMMONLY USED GROUND WIRE OF DISTRIBUTION NETWORKS UNDER VARIOUS OPERATING AND LOAD CONDITIONS
}

\author{
Tamás BAGI \\ Department of Safety Sciences, Research Group of Applied Disciplines and Technologies in Energetics, \\ Óbuda University, Bécsi út 96, H-1034 Budapest, Hungary, tel. +36 20342 3084, E-mail: bagi.tamas@elinor.hu
}

\begin{abstract}
Climate change is increasingly leading to extreme weather conditions that threaten the secure operation of high-voltage transmission and distribution networks. In recent years, significant damage and danger have been caused by icing of wires and damage or collapse of tower structures. Damage to the grid threatens the security of electricity supply. It is therefore appropriate to examine the appropriateness of the elements of the electricity network to the changed circumstances. Countries apply different methods to prevent the icing of phase conductors. In high voltage DC networks (e.g. in Russia and China) the de-icing of specified network sections can be accomplished with a simple solution, applying heating power. This method is not applicable in Hungary because we do not have HVDC network. For heating of phase conductors, a new method (the Dynamic Line Rating (DLR) method), based on changing the transmission capacity at HVAC networks, has been recently developed. However, I was not dealing with these methods because they are irrelevant to the de-icing of the ground wires of HVAC networks. Since there was no current flowing in the ground wires during normal operation and each tower is grounded, a new inductive warming method had to be developed. In this paper, I address the electrical and thermodynamic issues of this new method. In this article I mainly deal with the investigation of the ACSR type ground wire with 95/55 $\mathrm{mm}^{2}$ cross section, but the method can also be applied to phase conductors. During the investigations, the electrical parameters were determined by the LABVIEW software and the thermal calculations were carried out by Ansys Workbench software.
\end{abstract}

Keywords: ACSR, Ground Wire, Load Flow, LABVIEW

\section{INTRODUCTION}

Until 2013, we used versions of the MSZ 151 family of standards for the design of the high-voltage power lines and then switched to EUROCODE-based standards which already set new load and sizing guidelines in response to the changed extreme weather conditions.

These new standards concern not only to the design guidelines for high voltage transmission and distribution networks, but also to low and medium voltage networks.

Changes in standards usually mean stricter requirements. The wind force on the column structure and the forces transmitted from the wires increased, the load from the weight of the installers increased, and the requirements for the column structure were also tightened. Internal electrical safety distances, operating temperature and required conductor height for outdoor areas, etc. also changed.

In connection with this, several Hungarian and international standards deal with safe electrical load, wire structures, their heating, and the investigation of phase conductors and earth conductors. There are significant differences between the practical experience, the manufacturer calculations and the standard modelling results. The reasons for these differences may be the different material quality, the use of newer materials, the different manufacturing processes and the different theoretical considerations. There are several ways to obtain the information and data needed to verify the results. The first option is measurement and data collection, but it is a very long and expensive method. The other method is a computer simulation and modelling.

This article presents an investigation of a ground wire, in which the electrical part of the complex investigation has been performed using the program developed in
LABVIEW and its results concerning the ground wire using Ansys finite element thermal simulation.

\section{MATERIALS AND METHODS}

\subsection{The LABVIEW computational model}

The LABVIEW model is divided into two independent subsystems: the electrical and the thermal model. The parameters required for the construction of the electric model can be determined by using the knowledge of Electromagnetic Theory [21].

\subsubsection{Electrical model}

The electrical model is a multilayer, cylindersymmetrical model in conformity with twisted structure. Every layer contains a heat flow generator; accordingly, each heating of electrical origin should be determined by a layer. To determine the heat developing in each layer, the current in the given layer and the resistance should be calculated. When calculating the resistance of the wires for each layer, the resistance values given in standard MSZ 149-1 are assumed.

The i layer DC resistance:

$$
\begin{aligned}
& R_{i}=\rho_{i} \cdot \frac{l_{i}}{A_{i}}[\mathrm{Ohm}] \\
& A_{i}=\pi \cdot r_{i}^{2} \quad\left[\mathrm{~m}^{2}\right]
\end{aligned}
$$

where $\rho_{\mathrm{i}}$ is the Resistivity, $\mathrm{A}_{\mathrm{i}}$ is the Cross-Section, the $l_{i}$ is the length of the Wire and $r_{i}$ is the radius. Thus, it is necessary to determine the alternating current resistance $\mathrm{R}_{\mathrm{i}}$. The Heat Generation and the Electrical Power are obtained as follows: 
$P_{i}=I_{i}^{2} R_{i} \quad[W]$

\subsubsection{Alternating-Current Resistance}

Due to the skin effect, the efficient cross-section narrows and the alternating-current resistance $\left(\mathrm{R}_{\mathrm{AC}}\right)$ increases in comparison to the direct-current resistance $\left(\mathrm{R}_{\mathrm{DC}}\right)$. (The value of the $\delta$ skin-depth in case of aluminium is $\delta_{\mathrm{Al}}=12.03 \mathrm{~mm}$, in case of transformer sheet $(\mu=500)$ is $1.01 \mathrm{~mm}$ and in case of a steel thread with smaller relative permeability $(\mu \approx 100)$ is $\delta_{\mathrm{St}}=2.26 \mathrm{~mm}$, if the frequency of the current is $50 \mathrm{~Hz}$.)

With exception of the steel core wire, the individual layers can be approximated by a ring cylinder, where the wall thickness of the cylinder is equal to the diameter of the elemental thread, while the wall thickness being the same as that of the primary thread.

The relative wall thickness of a cylinder of a d thickness of $\mathrm{r}_{[\mathrm{i}+1]}$ an outer radius $\mathrm{v}$ :

$v=\frac{d[i]}{r[i+1]}$

The $\mathrm{i}$ layer $\mathrm{R}_{0 \mathrm{i}}$ is determined by the alternating-current impedance $\left(\mathrm{R}_{\mathrm{AC}}\right)$.

$Z=Z_{\text {real }}+j * Z_{\text {imag }}$

where $Z_{\text {real }}$ is the real part of the AC impedance $(\Omega)$, and $\mathrm{Z}_{\mathrm{imag}}$ is the imaginary of the $\mathrm{AC}$ impedance $(\mathrm{j} \omega \mathrm{L})$

$$
\begin{aligned}
& Z_{\text {real_i }}=R_{0 i} v\left[\frac{\operatorname{sh}(2 v)+\sin (2 v)}{\operatorname{ch}(2 v)-\cos (2 v)}+\frac{d}{2 r}\right] \\
& Z_{\text {imag_i }_{-}}=R_{0 i} v\left[\frac{\operatorname{sh}(2 v)-\sin (2 v)}{\operatorname{ch}(2 v)-\cos (2 v)}\right]
\end{aligned}
$$

The alternating-current resistance of the steel core wire ( $\mathrm{Z}_{\text {real0 }}$ ) can be calculated ${ }_{2}$ as in the previous case ${ }_{2}$ with $\mathrm{d}=\mathrm{r}$ substitution.

We can say that the current distribution of steel and aluminium (St-Al) is approx. 99\% - 1\%, if the wire is thicker and $98 \%-2 \%$, if it is thinner.

During the calculation of the distribution of the current inside the wire is calculated, we take two layers into consideration: the steel layer and the aluminium layer, because the distribution between these two layers can be expressed quite simply. First, we determine the currents in these two layers and then we break them down also taking into account the skin effect.

The skin depths are $\delta_{\mathrm{St}}=2,26 \mathrm{~mm}$ and $\delta_{\mathrm{Al}}=12,03 \mathrm{~mm}$. The relative permeability are, respectively, $\mu_{\mathrm{St}}=100$ and $\mu_{\mathrm{Al}}=1$.

$$
\begin{aligned}
& \alpha=\sqrt{\frac{m_{S t} \cdot \rho_{S t}}{m_{A l} \cdot \rho_{A l}}} \\
& v=\frac{d_{A l}}{\delta_{A l}}
\end{aligned}
$$

where $m_{S t}$ is the weight of the steel layer, $m_{A l}$ is the weight of the aluminium layer, $\rho_{S t}$ is the specific resistance of the steel wire, $\rho_{A l}$ is the specific resistance of the aluminium wire, $d_{A l}$ is the thickness of the aluminium layer and $\delta_{A l}$ the skin depth of the aluminium layer.

The ratio of the steel layers to the total flow is (10):

$$
=\frac{I_{\mathrm{St}}=}{(\operatorname{ch}(v)+\alpha \cdot \operatorname{sh}(v)) \cos (v)+j(\operatorname{sh}(v)+\alpha \cdot \operatorname{ch}(v)) \sin (v)}
$$

The current of the aluminium layers are given by (11):

$I_{A l}=I-I_{S t}$

This requires calculation with complex numbers, where both the absolute value and the phase-angle, or the real and the imaginary parts have to be determined. There is a demonstrable phase shift between the steel and the aluminium layer. Naturally, if the wire has a different structure, then first the current of the inner aluminium layer has to be determined with the given expression and material-properties, then the current in the steel can be obtained with a simple subtraction.

It should be noted that this relationship of the flow distribution was originally defined as a two-layered half space. A much more complicated Bessel function solution for the cylinder would give a more accurate value. The approximate error is not significant to aluminium around the centre, so that the steel core wire is larger by approx. 10-20\%. But, luckily, due to the impact and the material characteristics, only small currents are taking place here. Furthermore, the model does not take into account that the concentric cylinders of thickness $d$ are not compact but comprises elementary fibres of circular cross-section. This latter fact can only be taken into consideration in the system by the DC or AC resistors.

There is a demonstrable phase shift within the steel and the aluminium, but it is not considerable, so the current distribution can directly be calculated, on the basis of the absolute values, by the following expression. The $J$ current density in $z$ depth compared to the $J_{o}$ surface-value is:

$J(z)=J_{0} \cdot e^{-z / \delta}$

With this context, the current per layer can be determined by iteration, separately for the steel layers and separately within the aluminium (if it is multi-layered). Having calculated the complex current of $i$ layers, we take the absolute value, and then we get the heat per layers.

$P=\left|I_{i}\right|^{2} \cdot R_{i}$

$P=i_{i}^{2}(t) \cdot R_{i}(t)$

The time function $R_{i}(t)$ means that the resistance value changes with the known relationship:

$R_{i}=R_{20 i} \cdot(1+\alpha \cdot \Delta T)$ 
where $R_{20 i}$ is the DC Resistance measured at $20^{\circ} \mathrm{C}, \alpha$ is the material-dependent heat factor of the resistance and $\Delta T$ is the temperature change compared to $20^{\circ} \mathrm{C}$.

\subsubsection{Eddy Current and Hysteresis Loss}

In addition to the heat developing at resistive resistance, the eddy currents in the steel core also develops heat. Similarly, the heat is produced in the steel by the transient magnetization of the alternating current period. For eddy currents, the model should be constructed so that for the steel core wire only the layer 1 (steel) current is taken into account with only all the aluminium layers surrounding it. This can be done because each steel layer shields each other relatively well. The eddy current loss is only calculated for the steel, because in case of aluminium it is smaller by 2-3 orders of magnitude than the in case of steel and the hysteresis loss in the case of aluminium does not actually exist.

$\frac{P}{V}=\frac{n^{2} \cdot I_{\text {csúcs }}^{2}}{\delta^{2} \cdot \gamma} \frac{1}{\xi^{2}} f(\xi)$

where $n=N / l$ is the number of threads per unit length, $\gamma$ is the specific conductivity, $\Delta T$ is the temperature change compared to $20^{\circ} \mathrm{C}$ and $\xi=r / \delta$ is a parameter.

$$
\begin{aligned}
& f(\xi)=\xi\left(1-\frac{1}{2 \xi}-\frac{1}{16 \xi}\right) \text { ha } \xi>1 \\
& f(\xi)=\frac{1}{4} \xi^{4} \text { ha } \xi<1
\end{aligned}
$$

The volume must be the real volume of the examined steel layer. The hysteresis loss is considerable only in case of steel, and is counted from the eddy current loss by the following expression:

$P_{h}=P_{\text {all }} \frac{\rho \cdot \eta \cdot v^{2}(\operatorname{sh}(v)+\sin (v))}{f \cdot \pi^{2} \cdot d^{2}(\operatorname{sh}(v)-\sin (v))}$

where $\eta \approx 250, f=50 \mathrm{~Hz}, v=\mathrm{d} / \delta, \rho$ is the specific resistance, $\mathrm{d}$ is the thickness of the steel layer (not the same as the layer diameter) and $\delta \quad$ is the skin-depth of steel.

\subsubsection{Thermal model}

The thermal model, similar to the electrical model, describes the behaviour of the wire as a system of concentric cylinders. However, at the same time it different because all the elements having significant heat capacity, heat resistance etc. have to be taken into consideration independently from their electrical behaviour.

Accordingly, the model takes into account the irregular stratum between the elementary threads with a concentric air cylinder. Due to the air layers and the fact that all layers (steel, aluminium, air) have to have the same thermal behaviour as the real part of the wire, there is a necessary difference between the thickness and the number of the layers of the electrical and the thermal model. [26],[27]

The thermal model handles the layers as homogenous, so inside the given layer the temperature and the material properties (specific heat, density, heat resistance, etc.) are constant.
The heat exchange is conductive. The heat conduction between any two neighbouring layers is determined by taking into account the half of the thickness of the given layers. The heat transfer between two neighbouring layers is given by (20) [22]:

$$
\dot{Q}_{i, i+1}=\frac{2 \cdot \pi \cdot L}{\frac{1}{\lambda_{i}} \cdot \ln \frac{r_{i}}{r_{i, k}}+\frac{1}{\lambda_{i+1}} \cdot \ln \frac{r_{i+1, k}}{r_{i}}} \cdot\left(t_{i}-t_{i+1}\right)
$$

where $\lambda_{i}, \lambda_{i+1}$ is the thermal conductivity factor of the layer $i$ and the layer $i+1, r_{i, k}, r_{i+1, k}$ is the radius of the centreline of the layer $i$ and the layer $i+1, r_{i}$ is the outer radius of the layer $i, t_{i}, t_{i+1}$ temperature of the layer $i$ and the layer $i+1$ and $L$ is the length of the wire.

The radius $r$ in the thermal model is $d / 2$ thermic symbol in the LABVIEW program mentioned below. The temperature variation of one layer is described by the following differential equation:

$\sum \dot{Q}_{i}=c_{i} \cdot m_{i} \cdot \frac{d t_{i}}{d \tau}$

where $\sum \dot{Q}_{i}$ is the sum of the heat streams of the layers $i, \frac{d t_{i}}{d \tau}$ is the temperature change of the layer $i, c_{i}$ is the specific heat of the layer $i$ and $\mathrm{m}_{\mathrm{i}}$ is the weight of the layer $i$.

Heat source is primarily the heat production of ohmic resistors in the secondary iron losses of steel wires, as well as the sun and heat transfer on the surface of the wire.

\section{IMPLEMENTATION OF THE ELECTRIC AND THERMAL MODELING, DISCUSSION AND RESULTS}

\subsection{The LABVIEW model}

A simulation framework, developed in LABVIEW, was used to solve the problem. The framework is able to manage any kinds of models given by differential equations and various control tasks. The fundamental properties of LABVIEW are the following: graphical programming language and the ability to develop high speed time-critical applications.

The thermal and electrical models described above were performed by the LABVIEW program with $95 / 55$ ACSR wire parameters. The running environment and run details of the program are as follows: [14]-[17]

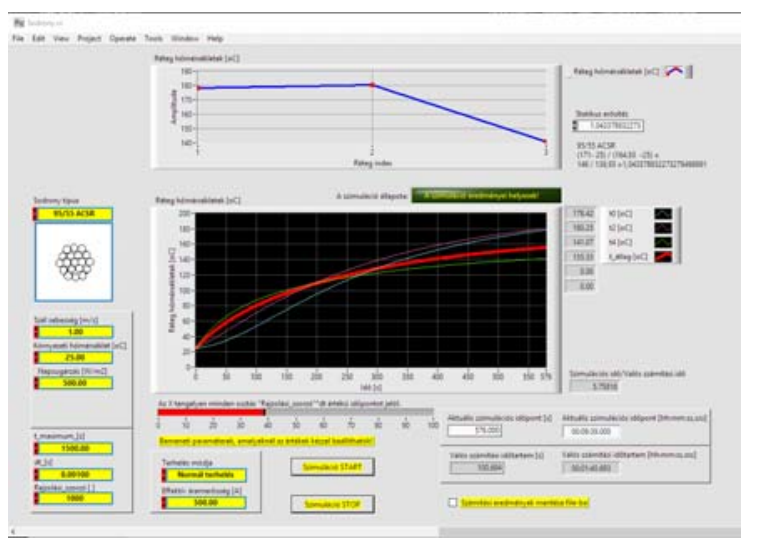

Fig. 1 LABVIEW program user interface 
Figure 1 shows the user interface of the program. The simulation parameters can be set on the left side of the image, and in the middle and on the right side you can see the real-time results, for example, the temperature of each layer or the current in the layers.

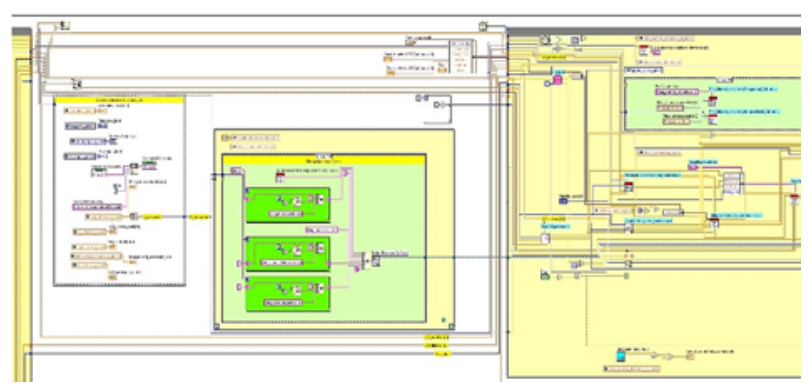

Fig. 2 Block Diagram Detail

Figure 2 shows how the program is built up. These blocks show how to build the program modularly and the connections between the modules. [1]-[13]

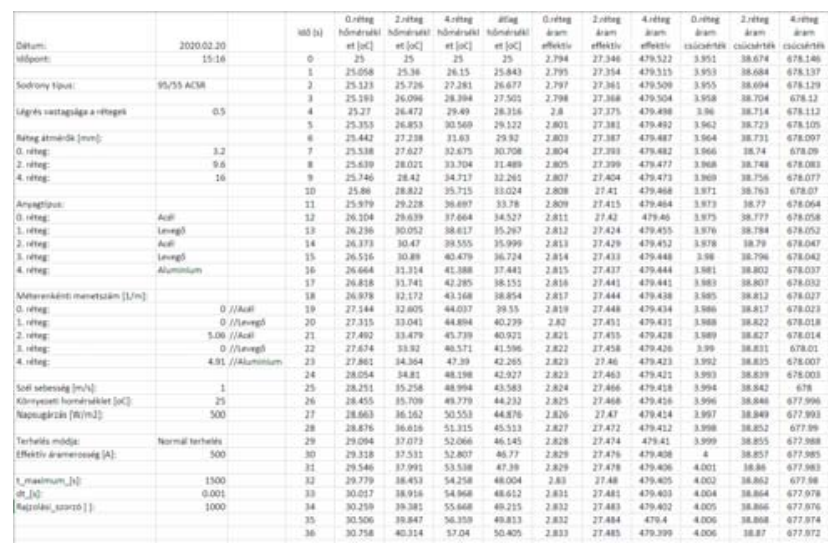

Fig. 3 Post-Run Results

The program can record the results of the run in a graphical way or in a file. Figure 3 shows how it looks in a file. This is very useful for ex-post evaluation.

\subsection{The ANSYS model - Thermal Analysis}

A simplified simulation was created to check the warming up and the melting procedure of the ice on an icy cable. [20]

The structure of the cable was simplified and assumed as a simple rod and the ice was a homogeneous ring. The cable material was aluminium. The thermal material properties of the aluminium cable can be found [23], while the relation of the ice properties and the temperature are shown in the Figure 4.

\section{Temperature $\left({ }^{\circ} \mathrm{C}\right)$}

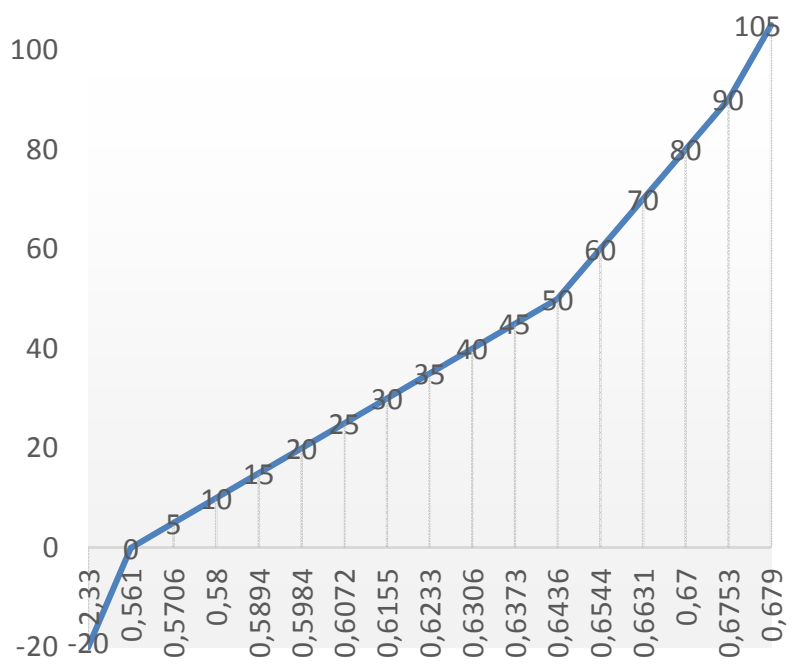

Fig. 4 Relation of the thermal conductivity and the temperature

A transient thermal analysis was performed by using ANSYS V18.2 Workbench software to check how the cable was warming up and melting the ice on its surface. [18],[19],[24],[25]

During the simulation, 20-node hexahedron elements were used. The element size was $4 \mathrm{~mm}$ on the cable and 2 $\mathrm{mm}$ on the ice. The contact type between the two elements was bounded (using MPC formulation) [1 - Ansys help ref.].

According to the analytical calculation, in the first part of the simulation the cable temperature was set to $102{ }^{\circ} \mathrm{C}$. Simultaneously, the warming cable started to warm up the ice ring.

The initial weight of the ice was $241 \mathrm{~g}$. During the simplified analysis uniform melting of the ice was assumed. Despite of the fact that this approach neglects the nonuniform real melting procedure, it gives a good approximation of the time we need to heat the cable to reach the full melting of the covering ice. The simplified criterion was the weight loss when the ice temperature increases.

The weight loss, because of the warming procedure in function of time, can be seen in Figure 5.

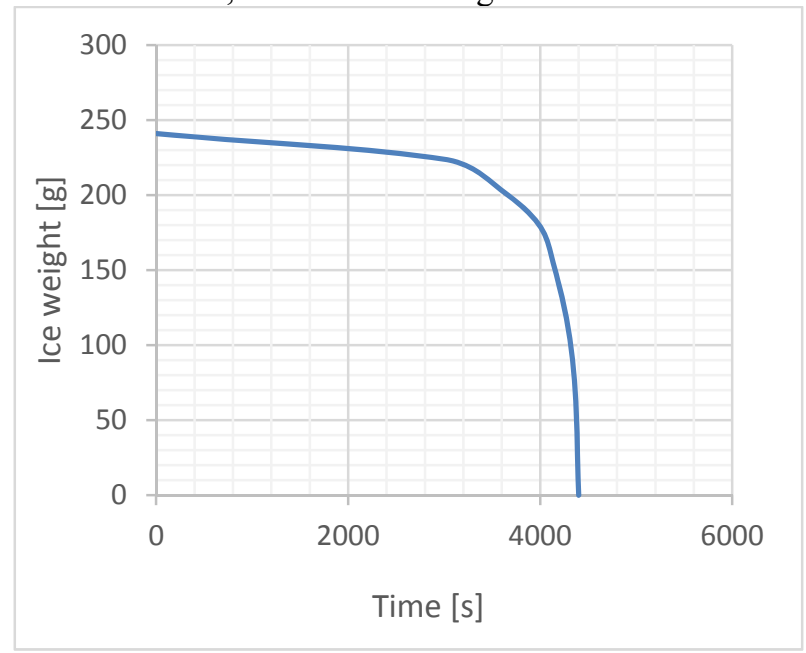

Fig. 5 Weight of the ice in function of time 
The heating up procedure visually can be seen in the next couple of figures.[18]
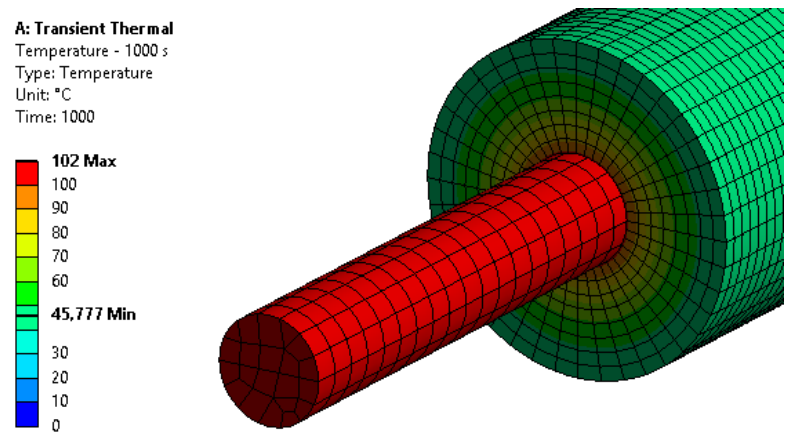

Fig. 6 Temperature conditions after 1000 seconds

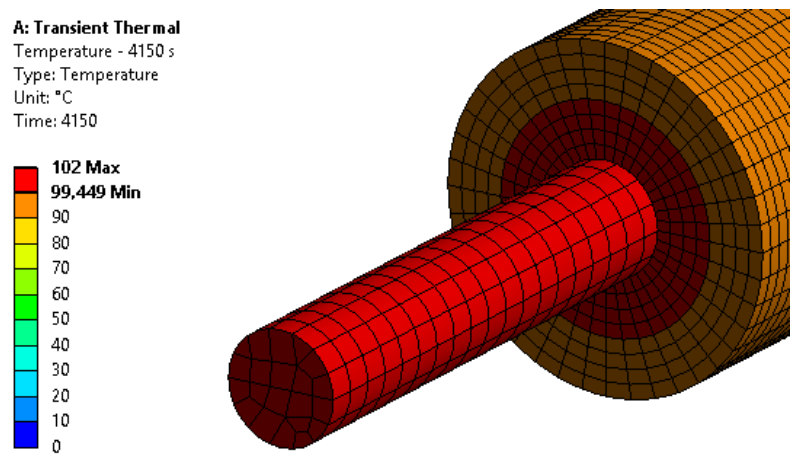

Fig. 7 Temperature conditions after 4270 seconds

Examining the warming up curve (Figure 8) we can see that the total melting occurs approx. 350-500 s after the heating procedure starts.

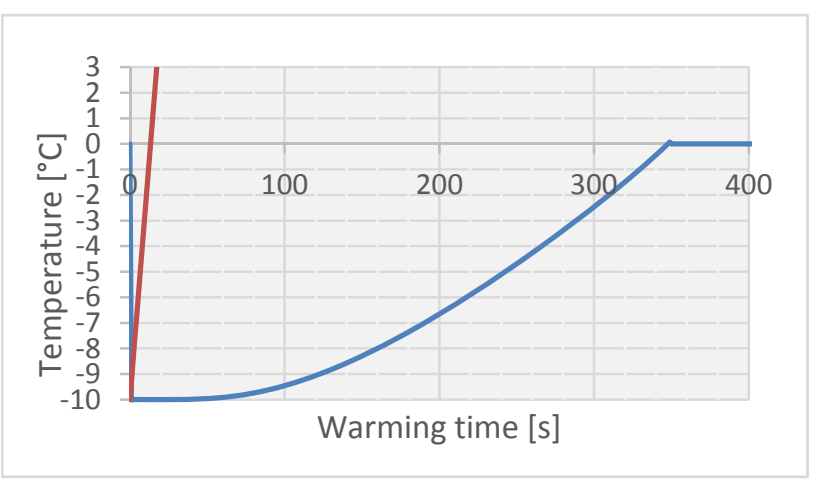

Fig. 8 Ice temperature conditions in first 350 seconds

\section{CONCLUSIONS}

The results obtained from each measurement and computer simulation are in good agreement and justify my previous hypothesis that the standard warming values for the electric load given by each wireline producer need to be clarified. The process of thawing ice crystals is well illustrated by the thermal analysis, and I am planning to refine the melting process further by refining this model (considering the weight and geometry change due to melting).

\section{ACKNOWLEDGMENTS}

Hereby, I would like to thank the Budapest University of Technology and Economics - Department of Electric Power Engineering, for ensuring all the necessary conditions to execute the laboratory measurements; $\mathrm{Mr}$ György Lipovszki Dr. forproviding a great support with his expertise and useful remarks/advise to develop the simulation program; Mr. Zoltán Hefner, E.ON Electrical Networks South Region, Regional Project Expert for providing me all the necessary wires.

\section{REFERENCES}

[1] MSZ 149-1:1983 Heavy current stranded conductors. General technical requirements and tests.

[2] MSZ 149-2:1983 Heavy current stranded conductors. Aluminium stranded conductor

[3] MSZ 149-3:1983 Heavy current stranded conductors. Aluminium alloy stranded conductor.

[4] MSZ 149-4:1983 Heavy current stranded conductors. Steel-reinforced aluminium conductor.

[5] MSZ 149-5:1983 Heavy current stranded conductors. Steel-reinforced aluminium alloy conductor.

[6] MSZ-05-33.7551:1986 Steel stranded grounding conductors and aluminium coated steel wire strand for protection and anchoring.

[7] MSZ-09-00.0315:1991 Testing methods determining the common parameters of stranded conductors and armatures.

[8] MSZ-09-00.0316:1991 Permissible thermal stresses for stranded aluminium conductor overhead lines.

[9] MSZ EN 50182 Conductors for overhead lines - Round wire concentric lay stranded conductors.

[10] DIN 57103:1982 Mechanical and Thermal Short Circuit Strength of Electrical Power Installations.

[11] DIN 48201/5 Aluminium Stranded Conductors (ASC).

[12] DIN 48201/6 Aluminium Alloy Stranded Conductors (AASC).

[13] DIN 48204 Aluminium Conductors Steel-Reinforced (ACSR).

[14] BAGI, T.-MORVA, G.: The Analysis of Issues Related to Ice Formation Experienced on Hungarian Power Transmission Lines, XXXIII. Cando Conference, Budapest, 2017, pp.78-79.

[15] BAGI, T.: A method presented by measurements to prevent harmful effects of icing forming on ground wires of high-voltage transmission lines, 34th Danubia-Adria Symposium on Advances in Experimental Mechanics, Trieste, 2017, pp. 1-3

[16] BAGI, T.: Examination of a Typical High Voltage Phase Conductor Under Various Operating and Load Conditions, International Scientific Conference on Advance in Mechanical Engineering, Debrecen, 2018 
[17] BAGI, T.: Warming and Load Testing of Steel Ground Wires in Laboratory, International IEEE Conference AND workshop in Óbuda on Electrical and Power Engineering, Budapest, 2018, pp. 283-287

[18] “ANSYS V18.2 Program Help.” Canonsburg, PA, USA, 2016-2017.

[19] ZWIERCZYK, P. T. - VÁRADI, K.: “Thermal Stress Analysis of a Railway Wheel in Sliding- Rolling Motion,” J. Tribol., vol. 136, no. 3, pp. 031401-031401, May 2014.

[20] Emergency Situations Management with the Support of Smart Metering/ Judit Pálfi, Peter Holcsik - 2016. In: Acta Polictechnica Hungarica, Vol. 13, No. 3, 2016, pp 195-206, DOI: 10.12700/APH.13.3.2016.3.11.

[21] SIMONYI, K. - ZOMBORY, L.: Elméleti Villamosságtan, Müszaki Könyvkiadó Budapest, 2000.

[22] https://www.scribd.com/document/367666335/Simonyi -Karoly-Zombory-Laszlo-Elmeleti-Villamossagtan2000 (Utolsó letöltés: 2019.09.20).

[23] BIHARI, P. : Termodinamika és höközlés, Budapest, 2016.

ftp://www.energia.bme.hu/pub/muszaki_hotan/jegyzetek/ Hotan_jegyzet_2016.pdf

(Utolsó letöltés: 2019.09.20)
[24] CALLISTER, W. D.: Materials science and engineering. J. Wiley 1994. London.

[25] KONDEPUDI, D. - PRIGOGINE, I.: Modern Thermodinamics, Wiley; 2 edition, 2014.

[26] PETRENKO, V. F.: Electrical Properties of Ice, U.S. Army Cold Regions Research and Engineering Laboratory, Thayer School of Engineering Dartmouth College, August 1993, NTIS, Springfield, Virginia 22161

[27] Ice - Thermal Properties, Engineering ToolBox, https://www.engineeringtoolbox.com/ice-thermalproperties-d_576.html (Last download: 2019.10.16)

Received February 05, 2020, accepted March 09, 2020

\section{BIOGRAPHIES}

Tamás Bagi was born on 20.08.1984. Budapest University of Technology and Economics - Department of Electric Power Engineering, Budapest (Hungary) graduated with Certified Electrical Engineer in 2009. Postgraduate diplomas in Engineer - Economist received from the Corvinus University of Budapest, Budapest (Hungary), in 2011. bagi.tamas@elinor.hu 